\title{
Depression in Cognitive Impairment
}

\author{
Laurel D. Pellegrino, Matthew E. Peters, Constantine G. Lyketsos, and Christopher M. \\ Marano \\ Department of Psychiatry and Behavioral Sciences, Division of Geriatric Psychiatry and \\ Neuropsychiatry, The Johns Hopkins University, 5300 Alpha Commons Drive, Baltimore, MD \\ 21224, USA \\ Matthew E. Peters: mpeter42@jhmi.edu
}

\begin{abstract}
Depression and cognitive disorders, including dementia and mild cognitive impairment, are common in the elderly. Depression is also a common feature of cognitive impairment although the symptoms of depression in cognitive impairment differ from depression without cognitive impairment. Pre-morbid depression approximately doubles the risk of subsequent dementia. There are two predominant, though not mutually exclusive, constructs linking pre-morbid depression to subsequent cognitive impairment: Alzheimer's pathology and the vascular depression hypothesis. When evaluating a patient with depression and cognitive impairment, it is important to obtain caregiver input and to evaluate for alternative etiologies for depressive symptoms such as delirium. We recommend a sequential approach to the treatment of depression in dementia patients: (1) a period of watchful waiting for milder symptoms, (2) psychosocial treatment program, (3) a medication trial for more severe symptoms or failure of psychosocial interventions, and (4) possible ECT for refractory symptoms.
\end{abstract}

\section{Keywords}

Dementia; Depression; Alzheimer's disease; AD; Mild cognitive impairment; MCI;

Neuropsychiatric symptoms; Genetics; Neuroimaging; Neurotrophins; Pharmacologic treatments;

Electroconvulsive therapy; ECT; Geriatric disorders; Psychiatry

\section{Introduction}

With an aging population, the interest in how to best maintain the health and well being of older individuals increases. Depression and dementia are both common disorders in the elderly. The lifetime prevalence of major depressive disorder has been recently estimated at $14.4 \%$ [1]. One estimate puts the prevalence of depression in those living in nursing homes at $54 \%$ [2]. The lifetime prevalence of all-cause dementia among individuals aged 71 or older has been estimated at $13.9 \%$, which comprises about 3.4 million individuals in the United States [3].

\footnotetext{
(C) Springer Science+Business Media New York 2013

Correspondence to: Matthew E. Peters, mpeter42 a jhmi . edu.

This article is part of the Topical Collection on Geriatric Disorders.

Compliance with Ethics Guidelines

Human and Animal Rights and Informed Consent This article does not contain any studies with human or animal subjects performed by any of the authors.

Conflict of Interest Laurel D. Pellegrino and Matthew E. Peters declare that they have no conflict of interest.
} 
Dementia is a syndrome of cognitive and functional decline. Though there are over 80 proposed causes of dementia, Alzheimer's disease (AD) is the most common, accounting for approximately $60-80 \%$ of dementia cases [4]. Vascular dementia is considered to be the second most common cause of dementia, though Alzheimer's and brain vascular pathology often co-exist, and it can be difficult to distinguish the two conditions apart. Given the aging population, and that risk of dementia increases with age, the annual incidence of $\mathrm{AD}$ and other dementias is projected to double by 2050 [4]. The aggregate payments for health care, long-term care, and hospice for people with dementia is expected to increase from $\$ 200$ billion in 2012 to $\$ 1.1$ trillion in 2050 .

In addition to the dementia syndrome, there is a syndrome of cognitive impairment without functional impairment, which is most commonly termed mild cognitive impairment (MCI) [5]. Many individuals with MCI will go on to develop dementia. In community samples, rates of conversion from MCI to dementia average 12 to $15 \%$ per year [6].

Though cognitive symptoms are the hallmark of dementia and MCI, neuropsychiatric symptoms are nearly universal. Among these neuropsychiatric symptoms, depression is one of the most common and troubling. Individuals with dementia and comorbid depression have decreased quality of life [7-9], as well as faster cognitive decline than those without depression [10]. Recognition and management of depression in cognitive impairment is crucial to providing optimized treatment for cognitive disorders, especially given the current lack of disease modifying treatments for $\mathrm{AD}$ and other neurodegenerative dementias.

The purpose of this review is to summarize and update the literature on depression in individuals with cognitive impairment. We will briefly review the relationship between premorbid depression and subsequent cognitive impairment followed by a discussion of the: (1) epidemiology and clinical characteristics of depression in individuals with cognitive impairment, (2) neurobiological changes in depression in cognitive impairment, and (3) clinical management of depression in cognitive impairment. As the most common cause of dementia and the subject of a large majority of dementia research, the review focuses on depression in $\mathrm{AD}$ as a prototype for the evaluation and management of depression in cognitive impairment.

\section{Relationship Between Pre-Morbid Depression and Subsequent Cognitive Impairment}

The relationship between depression prior to the onset of cognitive impairment and the subsequent development of cognitive impairment is an area of active study [11]. A detailed discussion is beyond the scope of this review, though the topic is extensively covered in several recent publications [12-14].

Briefly, cognitive impairment is a common feature of late-life depression (LLD) and often persists even after mood symptom remission [15-17]. Furthermore, substantial evidence suggests that LLD is both a risk factor for, as well as a prodrome of, dementia. For example, a meta-analysis estimated that depression doubles the risk of subsequent $\mathrm{AD}$ [12]. When separated out by all-cause dementia versus $\mathrm{AD}$ versus vascular dementia, a more recent meta-analysis found that LLD was associated with an odds ratio of 1.85 for all-cause dementia, 1.65 for $\mathrm{AD}$, and 2.52 for vascular dementia [18•].

There are two predominant, but not mutually exclusive, constructs regarding the relationship between LLD and dementia. The first construct centers on AD. As a prodrome, LLD may represent an initial, non-cognitive manifestation of AD. Evidence for LLD as an AD prodrome is the high conversion rate to dementia in individuals with LLD and co-occurring 
cognitive impairment $[15,16]$. Evidence for depression as an AD risk factor includes: (1) dementia risk increases as the length of time between diagnosis of first lifetime depression and diagnosis of $\mathrm{AD}$ increases [12] and (2) increased Alzheimer's pathology (amyloid plaques and neurofibrillary tangles) in AD patients with a lifetime depression history[19]. The second construct centers on the vascular depression hypothesis, initially postulated by both Alexopoulos and Krishnan [20, 21] with subsequent substantial supporting evidence (as reviewed by [22]). The hypothesis states that brain vascular disease can predispose, precipitate, or perpetuate depression in a subset of LLD patients. This brain vascular disease damages critical cortico-striatal circuits resulting in depression with cognitive impairment, particularly executive dysfunction, and poor antidepressant response.

The concept of depression as risk factor for cognitive impairment has major public health implications. For example, Barnes and Yaffe estimated that a $10 \%$ reduction in depression prevalence could result in 68,000 fewer AD cases in the USA and 326,000 fewer cases worldwide [23•]. Furthermore, it is unknown whether treating depression reduces risk of cognitive impairment, and preliminary epidemiologic studies are mixed. A Danish study of 37,658 patients with a depression diagnosis treated with antidepressants reported that continued use of older antidepressants (primarily TCAs), but not newer antidepressants (primarily SSRIs), was associated with a decreased incidence of all-cause dementia and AD [24]. Conversely, a study of 6998 cognitively healthy, postmenopausal woman showed that those taking antidepressants at baseline had a $70 \%$ increased risk of incident MCI at followup [25].

\section{Epidemiology and Clinical Characteristics}

The estimated prevalence of depression in cognitive impairment varies based on study sample (e.g., clinical versus population) and method utilized to ascertain depression (e.g., rating scale versus structured clinical interview). Population studies, such as the Cache County Study of Memory Health and Aging, can serve as a guide. This large, longitudinal study of all individuals over age 65 in Cache County, Utah utilized the Neuropsychiatric Inventory [26] to assess depression and other neuropsychiatric symptoms. The Cache County Study reported a 30-day prevalence of depressive symptoms in $29.9 \%$ of participants with dementia, $16.9 \%$ of participants with cognitive impairment that do not meet criteria for dementia, and $4.9 \%$ of cognitively normal individuals [27]. The cumulative prevalence of depression in dementia over 5-years was $77 \%$ [28]. A recent Japanese population-based study similarly found increased depression symptoms in individuals with MCI compared to cognitively intact individuals [29]. Depression also appears to be relatively persistent with several studies showing about half of dementia patients with depression remain depressed when evaluated one year later [30, 31].

The symptoms of depression in cognitive impairment are often different from the symptoms of depression in the absence of cognitive impairment, resulting in a diagnostic dilemma. Multiple studies have compared symptom clusters in depressed patients with and without dementia, often with conflicting results. Noting these differences, Lyketsos et al. used latent class analysis to propose the "Affective syndrome of Alzheimer's disease" [32], which includes one or more symptoms of a core affective disturbance (defined as depression, irritability, anxiety or euphoria) combined with one or more less prominent associated symptoms (defined as aggression, psychomotor agitation, delusions, hallucinations, sleep disturbance or appetite disturbance). Subsequently, a National Institute of Mental Health (NIMH) working group proposed the provisional criteria for diagnosis of depression in Alzheimer's dementia (dAD) [33]. Modifying the DSM-IV criteria for a major depressive episode, the provisional dAD criteria state that 3 (not 5) of the following symptoms be present during the same 2 -week period and represent a change from previous functioning: 
(1) clinically significant depressed mood, (2) decreased positive affect or pleasure in response to social contacts and usual activities, (3) disruption in appetite, (4) disruption in sleep, (5) psychomotor changes, (6) fatigue or loss of energy, (7) feelings of worthlessness, hopelessness, or excessive or inappropriate guilt, (8) diminished ability to think or concentrate, (9) recurrent thoughts of death, suicidal ideation, plan or attempt, (10) social isolation or withdrawal (new), and (11) irritability (new). Furthermore, compared to the DSM-IV criteria, the provisional criteria do not require the presence of symptoms most of the day, nearly every day.

Subsequent studies compared the provisional dAD criteria to other diagnostic criteria. An observational study of referrals to a memory clinic found $13.4 \%$ of patients met DSM-IV criteria for a major depression and $27.4 \%$ met the provisional criteria [34]. A study of subjects from Alzheimer's Disease Research Centers reported that $44 \%$ met provisional criteria, $14 \%$ met DSM-IV major depression criteria, and $36 \%$ met DSM-IV criteria for major or minor depression. The provisional criteria correctly identified all participants meeting DSM-IV criteria for major depression and correlated well with major or minor depression [35]. A recent latent class analysis of memory clinic referrals reported three symptom clusters considered to represent DSM-IV major depression, DSM-IV minor depression (a more heterogeneous group), and no depression [36].

Based on the above studies, there appear to be at least two types of clinically significant depressive symptoms in AD -a core group meeting more stringent DSM-IV criteria for a major depressive episode and a second, larger but less-well defined group variably identified with different diagnostic criteria. Regardless of diagnostic criteria utilized, patients in either group could have clinically significant depressive symptoms, which can be diagnosed with careful clinical assessment and may benefit from treatment.

\section{Neurobiological Changes in Depression in Cognitive Impairment} Genetics

The epsilon 4 allele of the apolipoprotein E epsilon 4 gene (APOE-e4) is a well-established genetic risk factor for $\mathrm{AD}$ that appears to plays a role in neuropsychiatric symptoms.

Multiple studies connect APOE-e4 to both AD and depression, but negative studies exist as well (as reviewed by [37]). For example, a Norwegian study found that APOE-e4 was more common in depressed than non-depressed AD patients [38]. Depression and APOE-e4 may also have an additive risk in cognitive impairment. A cohort study of Korean community dwelling individuals found a synergistic interaction between depressive symptoms and the APOE-e 4 allele in increasing the incidence of dementia [39]. These two factors also had a synergistic effect in increased incidence of amnestic MCI [40].

\section{Neuroimaging}

The hypothalamic-pituitary-adrenal (HPA) axis is dysregulated in some individuals with depression, resulting in high levels of cortisol. Elevated cortisol is hypothesized to cause hippocampal atrophy, which is seen in AD. Decline in left hippocampal volume is faster in elderly patients with depression than in those without [41, 42]. Post-mortem analysis also shows hippocampal neuronal loss in patients with LLD [43].

In addition to hippocampal atrophy, white matter changes have been reported in patients with depression and cognitive impairment. MCI subjects with depressive symptoms exhibited increased white matter atrophy in AD affected brain regions (frontal, parietal, and temporal) compared to MCI subjects without depression. Furthermore, depressed subjects in the study had increased AD conversion [44]. O'Brien et al. noted a correlation between frontal lobe white matter hypodensities on brain computerized tomography (CT) scan and 
depression in AD [45]. Similarly, Mueller et al. reported an association between frontal white matter lesions and depressed mood in $\mathrm{AD}$ and vascular dementia [46].

Functional neuroimaging studies also demonstrate differences in depression. Partially remitted LLD patients with persistent cognitive impairment demonstrated reduced activation in AD affected neural networks (inferior frontal and dorsal anterior cingulate cortex, hippocampus, and insula) using functional magnetic resonance imaging (fMRI) [47]. Using single photon emission computed tomography (SPECT), AD patients with depression had reduced blood flow on PET imaging to their right orbitofrontal and inferior frontal gyri versus non-depressed AD patients [48]. Recent advances in position emission tomography (PET) imaging allow for the study of AD pathology in vivo. For example, using the radiotracer [(18)F]FDDNP, which bind both amyloid and tau, Kumar and colleagues reported significantly higher protein load overall, and in the posterior cingulate and lateral temporal regions, in elderly subjects with major depression versus healthy controls [49].

\section{Neurotrophins}

Brain derived neurotophic factor (BDNF) is implicated in pathophysiology of depression, including LLD where the BDNF Val66Met allele is associated with late-life depression [50]. This relationship appears to extend to depression in $\mathrm{AD}$ [51], in addition to a relationship between the BDNF 11757C allele and depression in AD [52, 53]. Transforming growth factor- beta1 (TGF- $\beta 1$ ) is implicated in depression and cognitive impairment [54]. In one study, the $\mathrm{C} / \mathrm{C}$ phenotype was associated with more than a twofold-increased risk of $\mathrm{AD}$, and, in AD patients with this allele, a fivefold increase in the risk of depression [55].

\section{Clinical Management}

\section{Assessment}

There are two unique aspects in the assessment of depression in cognitive impairment that bear mention. First, caregiver input is essential for adequate assessment of depressive symptoms in individuals with cognitive impairment. The patient may have deficits in shortterm recall, abstract thinking, or executive functioning making it difficult to articulate a depressed mood. However, caregiver report may be biased by caregiver symptoms, such as stress [56]. Therefore, caregivers may over report and patients may underreport symptoms. Thus, the clinician is advised to utilize both caregiver and patient input in assessing mood symptoms in cognitive impairment.

Second, is the need to evaluate for other potential etiologies for the symptoms. Conditions which may mimic depression include delirium (including secondary to adverse medication effect), psychomotor retardation associated with Parkinsonian syndromes, and apathy seen in many dementia syndromes. In the Cache County study, apathy had the highest point prevalence among neuropsychiatric symptoms of dementia and was often present in the absence of depressive symptoms [57].

\section{Pharmacologic Treatments}

The use of antidepressants in depressed patients with dementia is common, although clinical trial data do not consistently support their efficacy. Significantly, there have been two recent large, multicenter randomized placebo controlled trials that have failed to demonstrate the efficacy of antidepressants over placebo in depressed patients with dementia. In the "Depression in Alzheimer's Dementia Study-2" (DIADS-2), patients taking sertraline (maximum dose $125 \mathrm{mg}$ daily) had no significant improvement versus placebo after 12 weeks [58・• or 24 weeks [59]; nor did they demonstrate any improvement in cognitive testing [60]. Further subgroup analysis based on symptom cluster (DSM-IV major 
depressive episode versus provisional dAD criteria) [61] and genetic polymorphisms associated with mood disorders [62], also failed to show a difference between sertraline and placebo.

The "Health Technology Assessment Study of the use of Antidepressants for Depression in Dementia" (HTA-SADD) evaluated mirtazapine (maximum dose $45 \mathrm{mg}$ daily) versus sertraline (maximum dose $150 \mathrm{mg}$ daily) versus placebo in AD patients with depressive symptoms [63••]. Neither medication demonstrated statistically significant improvement compared to placebo at 13 or 39 weeks. The largest study of its kind to date, the HTASADD mimics many aspects of clinical practice, but included no subgroup analysis based on depression severity, leaving open the question of whether the treatment may be effective for patients with dementia and severe depression [64].

While antidepressants are generally well tolerated in patients with dementia [65], these negative clinical trials occur in the context of increasing safety concerns regarding antidepressant use in the elderly. In 2011, the Food and Drug Administration issued a Drug Safety Communication for citalopram with a new maximum recommended dose of $20 \mathrm{mg}$ daily in patients greater than 60 years old due to the potential for dose-dependent QT interval prolongation and Torsade de Pointes. A large UK population based study found that elderly patients with a new diagnosis of depression that received at least one prescription for an antidepressant had an increased risk of all-cause mortality [66]. The study also found no evidence for reduced risk of selected adverse events with newer antidepressants (including SSRIs) compared to TCAs with SSRIs demonstrating an increased hazard ratio for falls and hyponatremia compared to TCAs. Furthermore, a Dutch study of nursing home residents with dementia found a dose dependent risk of injurious falls with SSRIs, especially in combination with a hypnotic or sedative [67].

\section{Electroconvulsive Therapy}

Electroconvulsive therapy (ECT) may be the most efficacious and immediate treatment of depression in the elderly. It is well tolerated even in patients over 80 years of age [68]. However, few studies examine the use of ECT in depression with dementia. In a case series of 31 patients with depression and dementia, ECT improved mood to a clinically significant extent with minimal reports of worsening cognition or prolonged postictal delirium [69]. A subsequent case series of 44 patients, including patients with MCI and dementia, reported cognitive improvement in non-cognitively impaired patients 6 months post-ECT.

Interestingly, though group sizes were small and the finding did not reach statistical significance, cognition improved during ECT in dementia patients treated with cognitive enhancing medications but declined in the untreated dementia patients [70]. A recent review of ECT in dementia noted general positive outcomes but cautioned regarding variability in ECT methods, dementia diagnosis, and dementia severity in these studies, as well as the need for close cognitive monitoring and discussion of potential cognitive risks with patients and families [71].

\section{Non-pharmacologic Treatments}

Limited data suggest that several non-pharmacologic treatment strategies may be effective. Physical activity is one of the more common strategies proposed. While evidence is limited and inconsistent, a review of relevant studies suggests that, above a certain threshold of rigorousness, physical activity may have a positive effect on mood in these patients [72]. In one study, a 12-week yoga program was positively associated with an improvement in depressive symptoms [73]. 
Additionally, non-pharmacologic treatment strategies aimed at caregivers may have a positive effect on patient mood. An analysis of four studies shows that the provision of coping-strategy-based support for caregivers, with or without a tailored activity for the patient, had a small positive effect on dementia patients' quality of life [74].

For patients living in residential facilities, environment can impact mood. One study looked at the implementation of a nursing guideline that emphasizes increasing pleasant activities and reducing negative events in several psychogeriatric nursing home wards, and found a significant decrease in depressive symptoms in residents with depression and dementia [75]. An examination of similar facilities in the Netherlands found that depressive symptoms in residents correlated with the level of social engagement on the unit, but this effect disappeared when individual resident characteristics (e.g., age, gender, level of function, presence of a partner) were taken into account [76].

\section{Proposed Treatment Algorithm}

We recommend the following treatment approach [77]:

1. Consider watchful waiting for milder symptoms: An initial period of watchful waiting may be prudent for milder depression given the lack of evidence for pharmacologic therapy and the fact that patients in the placebo arms generally show improvement in depressive symptoms. For example, based on the $43 \%$ reduction in depression scores in the placebo group at 13 weeks in the HTA-SADD study, Brodaty recommends 13 weeks watchful waiting [78].

2. Implement a psychosocial treatment program: Given the evidence for efficacy with little to no downside, consider a tailor-made strategy of behavioral interventions for the patient combined with education and problem-solving strategies for the caregiver.

3. For more severe symptoms or if psychosocial treatments fail, start medication: Choose a medication with careful regard to the patient's comorbid conditions and the medication's side effect profile. While it is important to start with a low dose and gradually increase the prescription, it is also critical to reach an adequate dosage before declaring the medication a failure. Lastly, because evidence for efficacy is limited, it is essential to continually reassess the patient's condition and make decisions on the continued need for treatment based on the individual patient.

4. Consider electroconvulsive therapy (ECT) for the treatment-refractory patient: Any decision regarding ECT should include a thorough review of risks and benefits, including with caregivers.

\section{Conclusion}

Depression commonly occurs in individuals with cognitive impairment and represents an important target for treatment. There are two predominant and not mutually exclusive constructs linking pre-morbid depression to subsequent cognitive impairment: (1) late-life depression may represent an initial, non-cognitive manifestation of $\mathrm{AD}$ and (2) the vascular depression hypothesis, which states that brain vascular disease can predispose to both dementia and depression. In all likelihood, the relationship between depression and cognitive impairment is a result of the interaction of multiple variables. We recommend a sequential approach to the treatment of depression in dementia patients: (1) a period of watchful waiting for milder symptoms, (2) psychosocial treatment program, (3) a medication trial for more severe symptoms or if psychosocial interventions fail, and (4) possible ECT for refractory symptoms. 


\section{Acknowledgments}

This paper is supported in part by National Institutes of Health: MH095971 (Christopher M. Marano).

Constantine G. Lyketsos has received grant support (research or CME) from NIMH, National Institute on Aging, Associated Jewish Federation of Baltimore, Weinberg Foundation, Forest, GlaxoSmithKline, Eisai, Pfizer, AstraZeneca, Lilly, Ortho-McNeil, Bristol-Myers Squibb, Novartis, National Football League (NFL), Elan, Functional Neuromodulation, and Janssen; has received consultant/advisor fees from AstraZeneca, GlaxoSmithKline, Eisai, Novartis, Forest, Supernus, Adlyfe, Takeda, Wyeth, Lundbeck, Merz, Lilly, Pfizer, Genentech, Elan, NFL Players Association, NFL Benefits Office, Avanir, Zinfandel, and Bristol-Myers Squibb; and has received honorarium or travel support from Pfizer, Forest, GlaxoSmithKline, and Health Monitor.

Christopher M. Marano has received grant support from NIMH.

\section{Abbreviations}

$\begin{array}{ll}\text { AD } & \text { Alzheimer's disease } \\ \text { APOE- } 4 \text { 4 } & \text { apolipoprotein epsilon 4 gene } \\ \text { BDNF } & \text { brain derived neurotropic factor } \\ \text { CT } & \text { computerized tomography } \\ \text { dAD } & \text { depression in Alzheimer's dementia } \\ \text { DIADS-2 } & \text { Depression in Alzheimer's Dementia Study - 2 } \\ \text { ECT } & \text { electroconvulsive therapy } \\ \text { fMRI } & \text { functional magnetic resonance imaging } \\ \text { HPA } & \text { hypothalamic-pituitary-adrenal } \\ \text { HTA-SADD } & \text { Health Technology Assessment Study of the use of Antidepressants for } \\ \text { LLD } & \text { Depression in Dementia } \\ \text { MCI } & \text { late-life depression } \\ \text { NIMH } & \text { mild cognitive impairment } \\ \text { PET } & \text { National Institute of Mental Health } \\ \text { SPECT } & \text { positron emission tomography } \\ \text { TGF- } \beta \text { 1 } & \text { single photon emission computed tomography }\end{array}$

\section{References}

Papers of particular interest, published recently, have been highlighted as:

- Of importance

•• Of major importance

1. Kessler RC, Petukhova M, Sampson NA, et al. Twelve-month and lifetime prevalence and lifetime morbid risk of anxiety and mood disorders in the united states. Int J Methods Psychiatr Res. 2012; 21:169-84. [PubMed: 22865617]

2. Morrell CJ, Curran S, Topping A, et al. Identification of depressive disorder among older people in care homes - a feasibility study. Prim Health Care Res Dev. 2011; 12:255-65. [PubMed: 21798123]

3. Plassman BL, Langa KM, Fisher GG, et al. Prevalence of dementia in the united states: The aging, demographics, and memory study. Neuroepidemiology. 2007; 29:125-32. [PubMed: 17975326] 
4. 2012 Alzheimer's disease facts and figures. Washington, D.C: Alzheimer's Association; 2012.

5. Petersen RC, Smith GE, Waring SC, et al. Mild cognitive impairment: Clinical characterization and outcome. Arch Neurol. 1999; 56:303-8. [PubMed: 10190820]

6. Tuokko H, Frerichs RJ. Cognitive impairment with no dementia (CIND): Longitudinal studies, the findings, and the issues. Clin Neuropsychol. 2000; 14:504-25. [PubMed: 11262720]

7. Winter Y, Korchounov A, Zhukova TV, Bertschi NE. Depression in elderly patients with alzheimer dementia or vascular dementia and its influence on their quality of life. J Neurosci Rural Pract. 2011; 2:27-32. [PubMed: 21716831]

8. Sheehan BD, Lall R, Stinton C, et al. Patient and proxy measurement of quality of life among general hospital in-patients with dementia. Aging Ment Health. 2012; 16:603-7. [PubMed: 22360734]

9. Karttunen K, Karppi P, Hiltunen A, et al. Neuropsychiatric symptoms and quality of life in patients with very mild and mild alzheimer's disease. Int J Geriatr Psychiatry. 2011; 26:473-82. [PubMed: 21445998]

10. Rapp MA, Schnaider-Beeri M, Wysocki M, et al. Cognitive decline in patients with dementia as a function of depression. Am J Geriatr Psychiatry. 2011; 19:357-63. [PubMed: 20808140]

11. Steffens DC, Otey E, Alexopoulos GS, et al. Perspectives on depression, mild cognitive impairment, and cognitive decline. Arch Gen Psychiatry. 2006; 63:130-8. [PubMed: 16461855]

12. Ownby RL, Crocco E, Acevedo A, et al. Depression and risk for alzheimer disease: Systematic review, meta-analysis, and metaregression analysis. Arch Gen Psychiatry. 2006; 63:530-8. [PubMed: 16651510]

13. Butters MA, Young JB, Lopez O, et al. Pathways linking late-life depression to persistent cognitive impairment and dementia. Dialogues Clin Neurosci. 2008; 10:345-57. [PubMed: 18979948]

14. Byers AL, Yaffe K. Depression and risk of developing dementia. Nat Rev Neurol. 2011; 7:323-31. [PubMed: 21537355]

15. Alexopoulos GS, Meyers BS, Young RC, et al. The course of geriatric depression with "reversible dementia": A controlled study. Am J Psychiatry. 1993; 150:1693-9. [PubMed: 8105707]

16. Alexopoulos GS, Young RC, Meyers BS. Geriatric depression: Age of onset and dementia. Biol Psychiatry. 1993; 34:141-5. [PubMed: 8399805]

17. Bhalla RK, Butters MA, Mulsant BH, et al. Persistence of neuropsychologic deficits in the remitted state of late-life depression. Am J Geriatr Psychiatry. 2006; 14:419-27. [PubMed: 16670246]

18•. Diniz BS, Butters MA, Albert SM, et al. Late-life depression and risk of vascular dementia and alzheimer's disease: Systematic review and meta-analysis of community-based cohort studies. $\mathrm{Br}$ J Psychiatry. 2013; 202:329-35. This meta-analysis of 23 studies concluded that late-life depression is associated with an increased risk for all-cause dementia, vascular dementia, and AD. [PubMed: 23637108]

19. Rapp MA, Schnaider-Beeri M, Grossman HT, et al. Increased hippocampal plaques and tangles in patients with alzheimer disease with a lifetime history of major depression. Arch Gen Psychiatry. 2006; 63:161-7. [PubMed: 16461859]

20. Alexopoulos GS, Meyers BS, Young RC, et al. 'Vascular depression' hypothesis. Arch Gen Psychiatry. 1997; 54:915-22. [PubMed: 9337771]

21. Krishnan KR, Hays JC, Blazer DG. MRI-defined vascular depression. Am J Psychiatry. 1997; 154:497-501. [PubMed: 9090336]

22. Culang-Reinlieb ME, Johnert LC, Brickman AM, et al. MRI-defined vascular depression: A review of the construct. Int J Geriatr Psychiatry. 2010

23•. Barnes DE, Yaffe K. The projected effect of risk factor reduction on alzheimer's disease prevalence. Lancet Neurol. 2011; 10:819-28. This review summarizes the evidence regarding modification of seven potentially modifiable risk factors for AD: diabetes, midlife hypertension, midlife obesity, smoking, depression, cognitive inactivity or low educational attainment, and physical inactivity. Based on these analyses, up to half of AD cases worldwide and in the US are potentially attributable to these seven factors. [PubMed: 21775213]

24. Kessing LV, Forman JL, Andersen PK. Do continued antidepressants protect against dementia in patients with severe depressive disorder? Int Clin Psychopharmacol. 2011; 26:316-22. [PubMed: 21876440] 
25. Goveas JS, Hogan PE, Kotchen JM, et al. Depressive symptoms, antidepressant use, and future cognitive health in postmenopausal women: The women's health initiative memory study. Int Psychogeriatr. 2012; 24:1252-64. [PubMed: 22301077]

26. Cummings JL, Mega M, Gray K, et al. The neuropsychiatric inventory: Comprehensive assessment of psychopathology in dementia. Neurology. 1994; 44:2308-14. [PubMed: 7991117]

27. Peters ME, Rosenberg PB, Steinberg M, et al. Prevalence of neuropsychiatric symptoms in CIND and its subtypes: The cache county study. Am J Geriatr Psychiatry. 2012; 20:416-24. [PubMed: 22522960]

28. Steinberg M, Shao H, Zandi P, et al. Point and 5-year period prevalence of neuropsychiatric symptoms in dementia: The cache county study. Int J Geriatr Psychiatry. 2008; 23:170-7. [PubMed: 17607801]

29. Hidaka S, Ikejima C, Kodama C, et al. Prevalence of depression and depressive symptoms among older japanese people: Comorbidity of mild cognitive impairment and depression. Int J Geriatr Psychiatry. 2012; 27:271-9. [PubMed: 21448864]

30. Garre-Olmo J, Lopez-Pousa S, Vilalta-Franch J, et al. Evolution of depressive symptoms in alzheimer disease: One-year follow-up. Alzheimer Dis Assoc Disord. 2003; 17:77-85. [PubMed: 12794384]

31. Starkstein SE, Mizrahi R, Garau L. Specificity of symptoms of depression in alzheimer disease: A longitudinal analysis. Am J Geriatr Psychiatry. 2005; 13:802-7. [PubMed: 16166410]

32. Lyketsos CG, Breitner JC, Rabins PV. An evidence-based proposal for the classification of neuropsychiatric disturbance in alzheimer's disease. Int J Geriatr Psychiatry. 2001; 16:1037-42. [PubMed: 11746649]

33. Olin JT, Schneider LS, Katz IR, et al. Provisional diagnostic criteria for depression of alzheimer disease. Am J Geriatr Psychiatry. 2002; 10:125-8. [PubMed: 11925273]

34. Vilalta-Franch J, Garre-Olmo J, Lopez-Pousa S, et al. Comparison of different clinical diagnostic criteria for depression in alzheimer disease. Am J Geriatr Psychiatry. 2006; 14:589-97. [PubMed: 16816012]

35. Teng E, Ringman JM, Ross LK, et al. Diagnosing depression in alzheimer disease with the national institute of mental health provisional criteria. Am J Geriatr Psychiatry. 2008; 16:469-77. [PubMed: 18515691]

36. Starkstein SE, Dragovic M, Jorge R, et al. Diagnostic criteria for depression in alzheimer disease: A study of symptom patterns using latent class analysis. Am J Geriatr Psychiatry. 2011; 19:551-8. [PubMed: 21606898]

37. Panza F, Frisardi V, Seripa D, et al. Metabolic syndrome, mild cognitive impairment, and dementia. Curr Alzheimer Res. 2011; 8:492-509. [PubMed: 21605050]

38. Fritze F, Ehrt U, Sonnesyn H, et al. Depression in mild dementia: Associations with diagnosis, APOE genotype and clinical features. Int J Geriatr Psychiatry. 2011; 26:1054-61. [PubMed: 21905099]

39. Kim JM, Stewart R, Kim SY, et al. Synergistic associations of depression and apolipoprotein E genotype with incidence of dementia. Int J Geriatr Psychiatry. 2011; 26:893-8. [PubMed: 21845591]

40. Caracciolo B, Backman L, Monastero R, et al. The symptom of low mood in the prodromal stage of mild cognitive impairment and dementia: A cohort study of a community dwelling elderly population. J Neurol Neurosurg Psychiatry. 2011; 82:788-93. [PubMed: 21212108]

41. den Heijer T, Tiemeier H, Luijendijk HJ, et al. A study of the bidirectional association between hippocampal volume on magnetic resonance imaging and depression in the elderly. Biol Psychiatry. 2011; 70:191-7. [PubMed: 21641582]

42. Steffens DC, McQuoid DR, Payne ME, Potter GG. Change in hippocampal volume on magnetic resonance imaging and cognitive decline among older depressed and nondepressed subjects in the neurocognitive outcomes of depression in the elderly study. Am J Geriatr Psychiatry. 2011; 19:412. [PubMed: 20808107]

43. Tsopelas C, Stewart R, Savva GM, et al. Neuropathological correlates of late-life depression in older people. Br J Psychiatry. 2011; 198:109-14. [PubMed: 21282780] 
44. Lee GJ, Lu PH, Hua X, et al. Depressive symptoms in mild cognitive impairment predict greater atrophy in alzheimer's disease-related regions. Biol Psychiatry. 2012; 71:814-21. [PubMed: 22322105]

45. O’Brien J, Perry R, Barber R, et al. The association between white matter lesions on magnetic resonance imaging and noncognitive symptoms. Ann NY Acad Sci. 2000; 903:482-9. [PubMed: 10818542]

46. Mueller SG, Mack WJ, Mungas D, et al. Influences of lobar gray matter and white matter lesion load on cognition and mood. Psychiatry Res. 2010; 181:90-6. [PubMed: 20074914]

47. Wang L, Potter GG, Krishnan RK, et al. Neural correlates associated with cognitive decline in latelife depression. Am J Geriatr Psychiatry. 2012; 20:653-63. [PubMed: 22157280]

48. Kang JY, Lee JS, Kang H, et al. Regional cerebral blood flow abnormalities associated with apathy and depression in alzheimer disease. Alzheimer Dis Assoc Disord. 2012; 26:217-24. [PubMed: 21959363]

49. Kumar A, Kepe V, Barrio JR, et al. Protein binding in patients with late-life depression. Arch Gen Psychiatry. 2011; 68:1143-50. [PubMed: 22065530]

50. Taylor WD, Zuchner S, McQuoid DR, et al. Allelic differences in the brain-derived neurotrophic factor Val66Met polymorphism in late-life depression. Am J Geriatr Psychiatry. 2007; 15:850-7. [PubMed: 17911362]

51. Borroni B, Grassi M, Archetti S, et al. BDNF genetic variations increase the risk of alzheimer's disease-related depression. J Alzheimers Dis. 2009; 18:867-75. [PubMed: 19661618]

52. Borroni B, Archetti S, Costanzi C, et al. Role of BDNF Val66Met functional polymorphism in alzheimer's disease-related depression. Neurobiol Aging. 2009; 30:1406-12. [PubMed: 18179845]

53. Zhang L, Fang Y, Zeng Z, et al. BDNF gene polymorphisms are associated with alzheimer's disease-related depression and antidepressant response. J Alzheimers Dis. 2011; 26:523-30. [PubMed: 21677379]

54. Caraci F, Copani A, Nicoletti F, Drago F. Depression and alzheimer's disease: Neurobiological links and common pharmacological targets. Eur J Pharmacol. 2010; 626:64-71. [PubMed: 19837057]

55. Caraci F, Bosco P, Signorelli M, et al. The CC genotype of transforming growth factor-beta1 increases the risk of late-onset alzheimer's disease and is associated with AD-related depression. Eur Neuropsychopharmacol. 2012; 22:281-9. [PubMed: 21924590]

56. Rosenberg PB, Mielke MM, Lyketsos CG. Caregiver assessment of patients' depression in alzheimer disease: Longitudinal analysis in a drug treatment study. Am J Geriatr Psychiatry. 2005; 13:822-6. [PubMed: 16166413]

57. Steinberg M, Sheppard JM, Tschanz JT, et al. The incidence of mental and behavioral disturbances in dementia: The cache county study. J Neuropsychiatry Clin Neurosci. 2003; 15:340-5. [PubMed: 12928510]

58••. Rosenberg PB, Drye LT, Martin BK, et al. Sertraline for the treatment of depression in alzheimer disease. Am J Geriatr Psychiatry. 2010; 18:136-45. This study found that sertraline did not demonstrate efficacy for the treatment of depression in patients with AD. In addition, its use was associated with an increased incidence of adverse events. The study concluded that selective serotonin reuptake inhibitors may be of limited value for treating depression in patients with AD. [PubMed: 20087081]

59. Weintraub D, Rosenberg PB, Drye LT, et al. Sertraline for the treatment of depression in alzheimer disease: Week-24 outcomes. Am J Geriatr Psychiatry. 2010; 18:332-40. [PubMed: 20220589]

60. Munro CA, Longmire CF, Drye LT, et al. Cognitive outcomes after sertaline treatment in patients with depression of alzheimer disease. Am J Geriatr Psychiatry. 2012; 20:1036-44. [PubMed: 23032478]

61. Drye LT, Martin BK, Frangakis CE, et al. Do treatment effects vary among differing baseline depression criteria in depression in alzheimer's disease study +/- 2 (DIADS-2)? Int J Geriatr Psychiatry. 2011; 26:573-83. [PubMed: 20672243]

62. Peters ME, Vaidya V, Drye LT, et al. Sertraline for the treatment of depression in alzheimer disease: Genetic influences. J Geriatr Psychiatry Neurol. 2011; 24:222-8. [PubMed: 22228829] 
63••. Banerjee S, Hellier J, Dewey M, et al. Sertraline or mirtazapine for depression in dementia (HTA-SADD): A randomised, multicentre, double-blind, placebo-controlled trial. Lancet. 2011; 378:403-11. This study on the utility of treatment with mirtazapine vs. sertraline vs. both for the treatment of depression in $\mathrm{AD}$ found absence of benefit compared with placebo and increased risk of adverse events. The study concluded that the use of antidepressants for first-line treatment of depression in AD should be reconsidered. [PubMed: 21764118]

64. Brodaty H. Antidepressant treatment in alzheimer's disease. Lancet. 2011; 378:375-6. [PubMed: 21764117]

65. Henry G, Williamson D, Tampi RR. Efficacy and tolerability of antidepressants in the treatment of behavioral and psychological symptoms of dementia, a literature review of evidence. Am J Alzheimers Dis Demen. 2011; 26:169-83.

66. Coupland C, Dhiman P, Morriss R, et al. Antidepressant use and risk of adverse outcomes in older people: Population based cohort study. BMJ. 2011; 343:d4551. [PubMed: 21810886]

67. Sterke CS, Ziere G, van Beeck EF, et al. Dose-response relationship between selective serotonin re-uptake inhibitors and injurious falls: A study in nursing home residents with dementia. Br J Clin Pharmacol. 2012; 73:812-20. [PubMed: 22486601]

68. Salzman C, Wong E, Wright BC. Drug and ECT treatment of depression in the elderly, 19962001: A literature review. Biol Psychiatry. 2002; 52:265-84. [PubMed: 12182932]

69. Rao V, Lyketsos CG. The benefits and risks of ECT for patients with primary dementia who also suffer from depression. Int J Geriatr Psychiatry. 2000; 15:729-35. [PubMed: 10960885]

70. Hausner L, Damian M, Sartorius A, Frolich L. Efficacy and cognitive side effects of electroconvulsive therapy (ECT) in depressed elderly inpatients with coexisting mild cognitive impairment or dementia. J Clin Psychiatry. 2011; 72:91-7. [PubMed: 21208587]

71. Oudman E. Is electroconvulsive therapy (ECT) effective and safe for treatment of depression in dementia? A short review. J ECT. 2012; 28:34-8. [PubMed: 22330702]

72. Thune-Boyle IC, Iliffe S, Cerga-Pashoja A, et al. The effect of exercise on behavioral and psychological symptoms of dementia: Towards a research agenda. Int Psychogeriatr. 2012; 24:1046-57. [PubMed: 22172121]

73. Fan JT, Chen KM. Using silver yoga exercises to promote physical and mental health of elders with dementia in long-term care facilities. Int Psychogeriatr. 2011; 23:1222-30. [PubMed: 21385519]

74. Cooper C, Mukadam N, Katona C, et al. Systematic review of the effectiveness of nonpharmacological interventions to improve quality of life of people with dementia. Int Psychogeriatr. 2012; 24:856-70. [PubMed: 22244371]

75. Verkaik R, Francke AL, van Meijel B, et al. The effects of a nursing guideline on depression in psychogeriatric nursing home residents with dementia. Int J Geriatr Psychiatry. 2011; 26:723-32. [PubMed: 21495077]

76. van Beek AP, Frijters DH, Wagner C, et al. Social engagement and depressive symptoms of elderly residents with dementia: A cross-sectional study of 37 long-term care units. Int Psychogeriatr. 2011; 23:625-33. [PubMed: 21073769]

77. Marano, C.; Rosenberg, P.; Lyketsos, C. Depression in dementia. In: Lavretsky, H.; Sajatovic, M.; Reynolds, C., editors. Late-life Mood Disorders. New York: Oxford: New York: Oxford University Press; 2013.

78. Brodaty H. Antidepressant treatment in alzheimer's disease. Lancet. 2011; 378:375-6. [PubMed: 21764117] 